\title{
New strategies in laser processing of TCOs for light management improvement in thin-film silicon solar cells
}

\author{
S. Lauzurica*a ${ }^{*}$ M. Lluscà ${ }^{\mathrm{b}}$, D. Canteli ${ }^{\mathrm{a}}$, M.I. Sánchez-Aniorte ${ }^{\mathrm{a}}$, J. López-Vidrier ${ }^{\mathrm{b}}$, S. Hernández ${ }^{\mathrm{b}}, \mathrm{J}$. \\ Bertomeu ${ }^{\mathrm{b}}, \mathrm{C}$. Molpeceres ${ }^{\mathrm{a}}$ \\ ${ }^{a}$ Centro Laser UPM. Campus Sur UPM. Ctra. Valencia Km. 7.300 Madrid 28031, Spain \\ ${ }^{b}$ Department of Applied Physics and Optics, Universitat de Barcelona, Barcelona 08028, Spain
}

\begin{abstract}
Light confinement strategies play a crucial role in the performance of thin-film (TF) silicon solar cells. One way to reduce the optical losses is the texturing of the transparent conductive oxide (TCO) that acts as the front contact. Other losses arise from the mismatch between the incident light spectrum and the spectral properties of the absorbent material that imply that low energy photons (below the bandgap value) are not absorbed, and therefore can not generate photocurrent. Up-conversion techniques, in which two sub-bandgap photons are combined to give one photon with a better matching with the bandgap, were proposed to overcome this problem.

In particular, this work studies two strategies to improve light management in thin film silicon solar cells using laser technology. The first one addresses the problem of TCO surface texturing using fully commercial fast and ultrafast solid state laser sources. Aluminum doped Zinc Oxide (AZO) samples were laser processed and the results were optically evaluated by measuring the haze factor of the treated samples. As a second strategy, laser annealing experiments of TCOs doped with rare earth ions are presented as a potential process to produce layers with up-conversion properties, opening the possibility of its potential use in high efficiency solar cells.
\end{abstract}

Keywords: Up-conversion Laser annealing, laser texturing, thin film photovoltaics, laser processing, light management..

\section{INTRODUCTION}

Laser technology has been thoroughly used in manufacturing of photovoltaic devices based on standard cell technology. The laser cutting of crystalline and polycrystalline silicon, the edge isolation techniques and laser buried contacts are usual in production processes. Amongst the technologies based on thin film (CdTe, CIGS or a-Si:H), laser techniques acquire a more relevant and clearly strategic role. More specifically, laser ablation techniques in thin film modules (laser scribing) have proven to be the most effective, and most industrially favorable for the monolithic interconnection processing of these devices [1,2]. With the laser technology there is still room for improvement in the efficiency of these devices, by leveraging the light management to increase the performance of TF solar cells. This light management consists of light scattering, light trapping and the effective use of the solar spectrum. In TF technology light management is mainly developed at the front contact TCO that collects the light that is led to the absorbent layer [3]. In this sense, laser technology can help to improve the light scattering by texturing the TCOs and can increase the effective absorption of the active layer (in this work a-Si:H) by laser annealing of rare earth (RE) doped TCOs, in order to enhance the photon absorption by up-conversion processes, where low energy photons of the solar spectrum are converted into higher energy ones.

\subsection{Laser texturing}

Use of textured and conducting front contacts in thin film silicon solar cells enhances photon absorption in active layers. Light scattering and trapping at the textured front surface leads to an increase of the optical path and consequently to an enhancement of the light absorption of the solar cell. . Different textured TCOs such as ZnO:B grown by LPCVD [4], $\mathrm{SnO}_{2}: \mathrm{F}$ grown by APCVD Asahi-U type [5], or $\mathrm{HCl}$ etching of sputtered $\mathrm{ZnO}$ :Al (AZO) [6] have been already widely studied. Currently there are two conventional processes for texturing TCOs, a crater-like texture when sputtering and etching or a pyramid-like structure when using LPCVD [7]. Laser texturing has the ability of designing customized patterns in a cost effective way introducing shaper surface geometries. In this work, sputtered AZO samples have been

Laser Processing and Fabrication for Solar, Displays, and Optoelectronic Devices III, edited by Edward W. Reutzel, Proc. of SPIE Vol. 9180, 918006 · (c) 2014 SPIE · CCC code: 0277-786X/14/\$18 · doi: 10.1117/12.2061712 
textured with different patterns and roughness by means of laser-processing and the morphological, optical and electrical properties of the resultant textures have been measured.

\subsection{Laser annealing for up-conversion}

Effective absorption of amorphous silicon-based solar cells is not able to absorb photons coming from energies lower than its band gap $(1.74 \mathrm{eV})$. One way to enhance photon absorption could be to convert these low energy photons into higher energy ones by using RE ions such as Er and $\mathrm{Yb}$. Rare earth materials were widely studied due to their photoluminescence properties, which occur as a result of their intra $4 \mathrm{f}-4 \mathrm{f}$ shell transitions [8]. In particular, Er and $\mathrm{Yb}$ co-doped systems [9-11] have the capability to work together to convert infrared radiation into visible light, because of the matching of their energy levels for $\lambda=980 \mathrm{~nm}$ [12]. Yb species act as the absorber ions due to their higher absorption coefficient, thus absorbing the incoming low-energy photons $(980 \mathrm{~nm})$, whereas Er species act as the emitter ions, releasing higher-energy photons $(480 \mathrm{~nm}, 550 \mathrm{~nm}, 660 \mathrm{~nm}$ ) (see Fig. 1). However it is known that Er local surrounding is critical to allow its $4 \mathrm{f}-4 \mathrm{f}$ transitions to occur, Er ions need to be surrounded by oxygen $\left(\mathrm{ErO}_{6}\right)$ forming a pseudooctahedral structure to act as optically active centers and often annealing treatments or $\mathrm{O}_{2}$ incorporation are required to change Er local structure in the form of $\mathrm{ErO}_{6}$ clusters [13]. In this work, $\mathrm{ZnO}$ was chosen as the host matrix and doped with $\mathrm{Er}$ and $\mathrm{Yb}$ ions in order to create a transparent and conducting up-converter material that could be used as the transparent conductive oxide (TCO) of the back contact and, therefore, exploit the up-conversion mechanism to enhance the efficiency of the solar cells. This TCO is normally used to improve the back reflector optical properties and act as a diffusion barrier, but in this work it will also act as an up-converter. Hence, $\mathrm{ZnO}$ :Er:Yb thin film has been deposited onto a glass substrate by means of RF magnetron sputtering and in order to optically activate the Er ions, a laser annealing treatment was performed, to be compare with conventional thermal treatment.

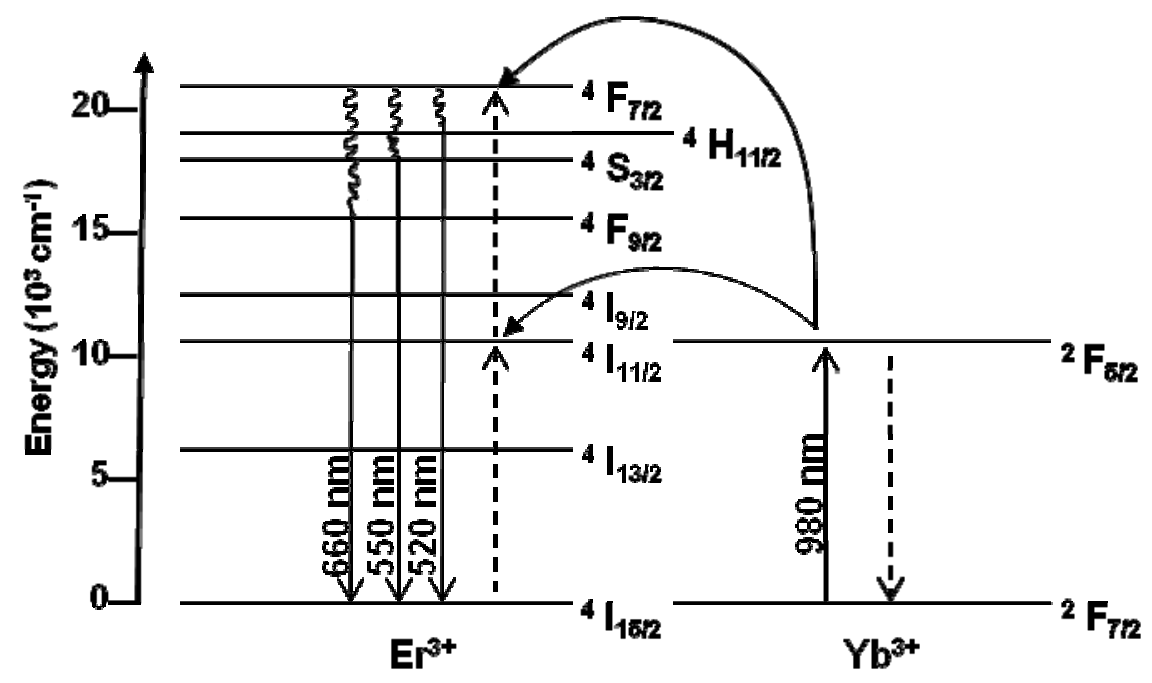

Figure 1. Generic representation of Er/Yb energy transfer; the full lines represent the radiative decay, the dashed ones represent energy transfer and the curly lines indicate multi-phonon relaxation. 2S+1L notation according to Russell-Saunders to refer the f states: spin $(\mathrm{S})$, orbital (L) and angular momentum (J) quantum numbers.

\section{EXPERIMENTAL}

\subsection{Preparation of TCOs samples}

For laser texturing experiments two samples of $\mathrm{ZnO}: \mathrm{Al}$ (2\%) of different thicknesses (500 and $1000 \mathrm{~nm}$ ) were grown onto $10 \times 10 \mathrm{~cm}^{2}$ Corning $1737 \mathrm{~F}$ glass substrates by means of DC magnetron sputtering at a power of $200 \mathrm{~W}$ and at a working pressure of $0.4 \mathrm{~Pa}(\mathrm{Ar})$. The substrates were kept at $300^{\circ} \mathrm{C}$ during deposition.

For laser annealing tests a $\mathrm{ZnO}: \mathrm{Er}: \mathrm{Yb}$ thin film of $800 \mathrm{~nm}$ thick, was deposited onto a $10 \times 10 \mathrm{~cm}^{2}$ Corning $1737 \mathrm{~F}$

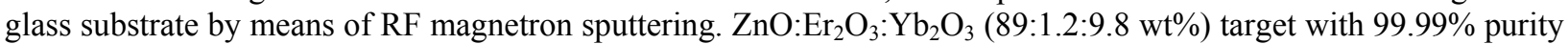
and a diameter of 3 inches was used for the deposition. The film was deposited without any intentional substrate 
heating, using a RF power of $120 \mathrm{~W}$, at a working pressure of $0.4 \mathrm{~Pa}(\mathrm{Ar})$ while the substrate rotation was kept at 10 $\mathrm{rpm}$ and the target to substrate distance was $12 \mathrm{~cm}$. Nine pieces of $10 \times 10 \mathrm{~mm}^{2}$ were cut from the central part of the sample, the first piece was kept without any annealing treatment (AS DEP) for comparison purposes; the second one was annealed in air atmosphere (AIR) at $800^{\circ} \mathrm{C}$ during 1 hour, and the seven remaining samples were irradiated with $532 \mathrm{~nm}$ CW laser.

\subsection{Laser systems}

Two different laser sources were used to carry out this work. (Table 1)

For laser texturing of the AZO, a diode pumped Q-switched laser with $\mathrm{Nd}: \mathrm{YVO}_{4}$ (Vanadate) lasing media crystal (HIPPO SPECTRA PHYSICS) working at its third harmonic $355 \mathrm{~nm}$ of wavelength was employed. The beam was delivered to the working area via steering mirrors, which direct the beam to a scanner head (Hurrycan II 14 SCANLAB) via the power attenuator AT4040. Before the entrance of the scanner head an iris is placed in order to remove the diffraction and aberration defects of the laser beam. The scanner head directs and focuses the beam onto the target via a lens with a focal length of $250 \mathrm{~mm}$.

For laser annealing experiments a CW (continuous wave) DPSS Nd:YVO 4 (Vanadate) laser system (MILLENNIA PRO SPECTRA-PHYSICS) was used. The beam delivery was performed in the same manner than for the HIPPO system.

\begin{tabular}{|c|c|c|c|}
\hline \multicolumn{4}{|c|}{ LASER SYSTEMS } \\
\hline \multicolumn{2}{|l|}{ 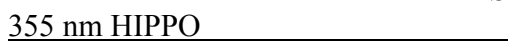 } & \multicolumn{2}{|c|}{$532 \mathrm{~nm}$ CW MILLENNIA } \\
\hline Average Power & $5 \mathrm{~W}$ at $50 \mathrm{KHz}$ & Average Power & $15 \mathrm{~W}$ \\
\hline Repetition rate & $15-300 \mathrm{KHz}$ & Mode & $\mathrm{TEM}_{00}$ \\
\hline \multicolumn{4}{|c|}{ Pulse-width nominal $<12 \mathrm{~ns}$ at $50 \mathrm{KHz}$} \\
\hline Mode & TEM $_{00}$ & & \\
\hline
\end{tabular}

Table 1. Laser system specifications.

\subsection{Characterization techniques}

The crystalline nature of the $\mathrm{ZnO}:$ Er:Yb films was analyzed using the $\mathrm{X}$-ray diffraction (XRD) technique used in BraggBrentano geometry ( $\theta-2 \theta$ scans) and the diffractometer was a PANalyticalX'Pert PRO MPD Alpha1 powder system, using $\mathrm{Cu} K_{\alpha}$ radiation, $\lambda=1.5406 \AA$..

The optical properties of the samples such as total transmittance $(T)$ and diffused transmittance $\left(T_{d}\right)$ were measured with a Perkin Elmer lambda 950 spectrophotometer equipped with a $150 \mathrm{~mm}$ integrating sphere. To evaluate the light scattering properties of the laser textured samples, the haze $(H)$ values were calculated following Eq.1

$$
H=\frac{T_{d}}{T} \cdot 100
$$

The up-conversion PL measurements of the ZnO:Er:Yb samples were performed using an EKSPLA PG122 optic parametric oscillator (OPO) with an output range of 420-2300 nm, which was pumped by the third harmonic of a Brilliant 5-ns-pulsed Nd:YAG laser (the peak power density was $\sim 10^{9} \mathrm{~W} \cdot \mathrm{cm}^{-2}$, for a spot diameter onto the sample of $100 \mu \mathrm{m})$. Using the OPO output at $980 \mathrm{~nm}$, aiming to excite the ${ }^{4} I_{11 / 2}$ and ${ }^{2} F_{5 / 2}$ levels of $\mathrm{Er}^{3+}$ and $\mathrm{Yb}^{3+}$ ions. The resulting luminescence spectra obtained in the visible range were acquired using a GaAs PMT. The excited PL study was carried out tuning the OPO output in the range from 950 to $1200 \mathrm{~nm}$, while monitoring the $660 \mathrm{~nm}$ emission line of Er with a monochromator, corresponding to the transition of the up-converted energy level.

The sheet resistance $(R s)$ of all the samples (laser textured and laser annealed) was measured by using a four-point probe system (Jandel RM3). In some of the textured samples, the $R s$ have been measured in two positions, placing the probes horizontal and also vertical (rotation of $90^{\circ}$ ) over the sample. Different measures have been done in every position, and an average of the $R s$ is presented.

Morhological characterization of the samples was measured employing a confocal microscope Leica Sensoscan from which the $\sigma_{\text {rms }}$ values were extracted. 


\section{RESULTS AND DISCUSSION}

\subsection{Laser texturing results}

Two sets of tests were performed over two AZO samples with different thickness, 500 and $1000 \mathrm{~nm}$. The first test execution was carried out on the $500 \mathrm{~nm}$ sample, where four different patterns (Fig. 2) were assessed.

Different patterns tested

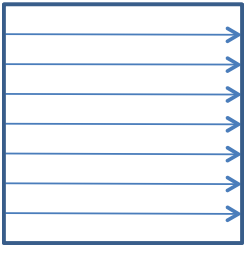

Parallel

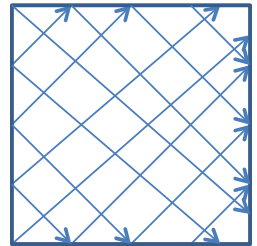

Rhombic

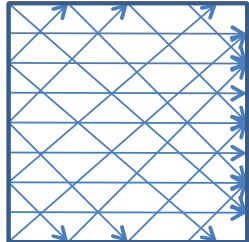

Triangular

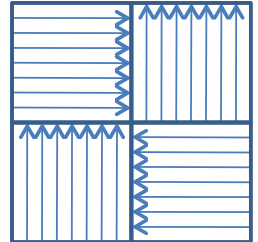

Combined parallel

Figure 2. Sketch of the patterns tested in AZO $500 \mathrm{~nm}$ of thickness.

Laser process was carried out at $355 \mathrm{~nm}$, speed process $85 \mathrm{~mm} / \mathrm{s}, 50 \mathrm{kHz}, 130 \mathrm{~mW}$ and peak fluence of $0.626 \mathrm{~J} / \mathrm{cm}^{2}$. The beam size on the sample was $23 \mu \mathrm{m}$ in diameter. Laser parameters remained constant for all the patterns assessed. The as-deposited film,500 $\mathrm{nm}$ thick, had a $R s$ of $7 \Omega / \square$ and an integrated transmittance $(T)$ in the range $400-800 \mathrm{~nm}$ of $83.83 \%$. The electrical and optical characterization of the tested patterns, the as-deposited sample and the commercial textured Asahi-U are shown in Table 2. The results demonstrate that the integrated $T$ of all the patterned samples is higher than that of the Asahi-U substrate and similar to the as-deposited sample indicating that the texturing did not spoil it. However, the $R s$ for the rhombic and triangular patterns clearly increases with respect to the as-deposited sample due to the ablation occurred during the texturing, the lack of material results in lower Rs values. Best results appear for line patterns where the $R s$ and the integrated $T$ were not compromised. In order to maintain a low sheet resistance but also a high haze factor, fundamental properties in the performance of TF solar cell technogies, a new batch of experiments was designed for a thicker film, The chosen patterns for this sample were parallel lines, with different pitch between them.

\begin{tabular}{|c|c|c|c|c|}
\hline Patterning & $\begin{array}{c}\text { Integrated } \boldsymbol{T} \mathbf{( 4 0 0} \\
\mathbf{n m - 8 0 0} \mathbf{~ n m}) \mathbf{( \% )}\end{array}$ & $\boldsymbol{\sigma}_{\text {rms }}(\mathbf{n m})$ & $\begin{array}{c}\text { Average Horizontal } \\
\boldsymbol{R} \boldsymbol{s}(\Omega / \square)\end{array}$ & $\begin{array}{c}\text { Average Vertical } \\
\boldsymbol{R s}(\Omega / \square)\end{array}$ \\
\hline Parallel & 81.89 & 53 & 30 & 30 \\
\hline Rhombic & 83.54 & 138 & $9.5 \mathrm{k}$ & $2.6 \mathrm{k}$ \\
\hline Triangular & 80.52 & 94 & $8.4 \mathrm{k}$ & 20 \\
\hline Combined parallel & 84.25 & 55 & 22 & 9.2 \\
\hline ASAHI_U & 78.26 & 31 & 9.2 & 7 \\
\hline As Deposited & 83.83 & 11 & & 7 \\
\hline
\end{tabular}

Table 2. Optical and electrical characterization of texturing patterns over sample AZO $500 \mathrm{~nm}$ of thickness.

The as-deposited $1000 \mathrm{~nm}$ thick film had a $R s$ of $8 \Omega / \square$ and an integrated transmittance within the range 400-800 $\mathrm{nm}(T)$ of $82.80 \%$. Laser processes were performed at $355 \mathrm{~nm}$, speed process of $85 \mathrm{~mm} / \mathrm{s}, 50 \mathrm{kHz}$ and at different powers. Results for parallel patterns over $1000 \mathrm{~nm}$ thickness film are shown in Table 3. In this case, the pitch between lines and the laser parameters were varied. Additional haze measurements at $600 \mathrm{~nm}$ were performed over the irradiated samples, considering good values of haze those above 9\% (value for Asahi-U). 


\begin{tabular}{|c|c|c|c|c|c|}
\hline Pitch & $\begin{array}{c}\text { Laser peak } \\
\text { fluence }\left(\mathrm{J} / \mathrm{cm}^{2}\right)\end{array}$ & $\begin{array}{c}\text { Integrated } T \\
(400-800 \mathrm{~nm}) \\
(\%)\end{array}$ & Haze@600 (\%) & $\sigma_{\mathrm{rms}}(\mathrm{nm})$ & $\begin{array}{c}\text { Rs (average value } \\
\text { of horizontal and } \\
\text { vertical } \\
\text { measurements) } \\
(\Omega / \square)\end{array}$ \\
\hline $10 \mu \mathrm{m}$ & 0.361 & 77,76 & 12,7 & 76 & 11 \\
\hline $10 \mu \mathrm{m}$ & 0.481 & 81,87 & 18,6 & 151 & 60 \\
\hline $15 \mu \mathrm{m}$ & 0.481 & 79,08 & 20,1 & 192 & 16,5 \\
\hline $20 \mu \mathrm{m}$ & 0.481 & 78,51 & 11,7 & 183 & 11,7 \\
\hline $20 \mu \mathrm{m}$ & 0.635 & 81,54 & 37,1 & 284 & 110 \\
\hline
\end{tabular}

Table 3. Optical and electrical characterization results of parallel patterns over sample AZO $1000 \mathrm{~nm}$ thick for different laser irradiation conditions.

Results shown in Table 3 demonstrated that haze values improve with higher values of $\sigma_{\text {rms }}$, albeit with higher laser energy the material ablated is more and the sheet resistance is increased.

\subsection{Laser annealing for up-conversion results}

Laser annealing experiments were carried out working just above the damage threshold of the film in order to avoid as much as possible the ablation and the loss of material that results in worst electrical characteristics of the film. The processes were performed at $532 \mathrm{~nm} \mathrm{CW}$ by scanning $10 \times 10 \mathrm{~mm}^{2}$ areas with parallel lines and varying the gap between them. The beam size on the sample was $29 \mu \mathrm{m}$ in diameter. Laser parameters are presented in Table 4.

\begin{tabular}{|c|c|c|c|c|c|}
\hline & Power $(\mathbf{W})$ & $\begin{array}{c}\text { Speed process } \\
(\mathbf{m m} / \mathbf{s})\end{array}$ & $\begin{array}{c}\text { Laser peak } \\
\text { fluence } \mathbf{( J / \mathbf { c m } ^ { 2 } )}\end{array}$ & Pitch $(\boldsymbol{\mu m})$ & $\begin{array}{c}\text { Number of } \\
\text { scans }\end{array}$ \\
\hline LAS1 & 1.5 & 50 & 8.12 & 10 & 1 \\
\hline LAS2 & 3.1 & 400 & 4.12 & 10 & 1 \\
\hline LAS3 & 2 & 75 & 7.65 & 60 & 1 \\
\hline LAS4 & 1.5 & 25 & 11.48 & 10 & 1 \\
\hline LAS5 & 2.4 & 50 & 10.27 & 30 & 1 \\
\hline LAS6 & 1.2 & 75 & 5.93 & 10 & 2 \\
\hline LAS7 & 1.2 & 75 & 5.93 & 10 & 4 \\
\hline
\end{tabular}

Fig. 2 presents the XRD patterns and the up-conversion PL spectra for the laser annealed samples that show lower upconversion intensity (LAS1, LAS2, LAS3), the as-deposited and air annealed samples-. All samples presented the most intense diffraction peak at around $2 \theta=34.4^{\circ}$, indicating a hexagonal wurtzite structure of $\mathrm{ZnO}$ with the $c$-axis perpendicular to the substrate and oriented preferentially along the [001] direction. Just in the air annealed sample a peak raised at $2 \theta=29.62^{\circ}$ corresponding to the (222) reflection of $\mathrm{Yb}_{2} \mathrm{O}_{3}$ cubic structure [14], no $\mathrm{Er}_{2} \mathrm{O}_{3}$ related peaks were seen, probably due to the rather small amount of Er content in the films (below the detection limit of the instrument). For LAS1, LAS2 and LAS3 the diffraction patterns are almost identical to the as deposited one indicating that the laser annealing was not affecting the macroscopic structure of the layers. The lack of rare earth phases in those patterns indicates that $\mathrm{Er}$ and/or $\mathrm{Yb}$ are replacing Zinc in the $\mathrm{ZnO}$ lattice or segregated to the grain boundaries $[15,16]$.

The up-conversion spectra show that the laser annealing is able to enhance the upconversion mechanism for LAS1 and LAS2, visible emissions at 480,520,550 and $660 \mathrm{~nm}$ are observed. Even the conventional annealing in air is the most effective in permitting Er $660 \mathrm{~nm}$ transition, the laser annealing allows also other Er emissions at 480, 520 and $550 \mathrm{~nm}$. By comparing the XRD patterns to the up-conversion PL, no relation seem to be between the presence of $\mathrm{Yb}_{2} \mathrm{O}_{3}$ and the RE ions activation. . 
a)

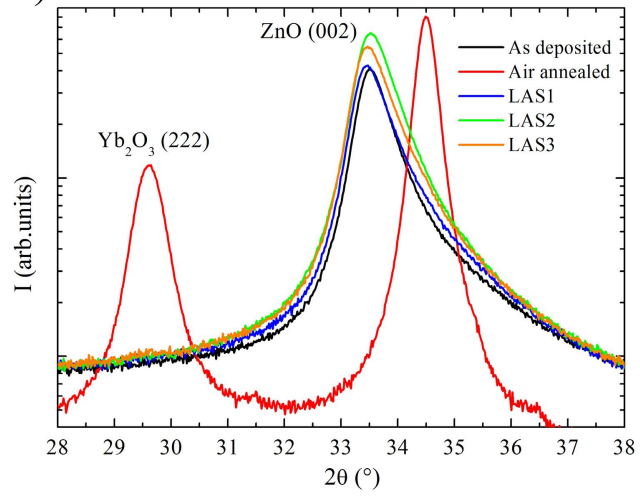

b)

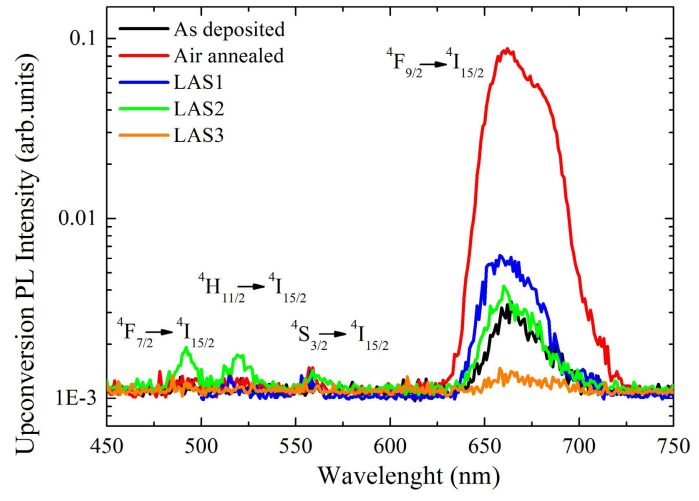

Figure 2. a) X-Ray diffraction patterns and b)up-conversion PL spectra in Logarithmic scale of the ZnO:Er:Yb thin film, as-deposited, annealed in air and laser-annealed at three different laser powers (LAS1, LAS2, LAS3).

Fig. 3. Illustrates, similarly to Fig.2, the XRD patterns and up-conversion PL spectra for the as-deposited sample, air annealed and LAS4, LAS5, LAS6 and LAS7. In contrast to LAS1, LAS2 and LAS3, the XRD patterns of the laser annealed samples present, for all the irradiation conditions, other $\mathrm{ZnO}$ peak orientations (001) and (101) a part from the typical (002). This suggests that these samples became more polycrystalline after the laser process, by means of the laser melting of the film and its subsequent cooling. It is also seen a desdoublement of the (002) $\mathrm{ZnO}$ peak that becomes more evident for the samples closer to the ablation limit.

Laser annealed samples show up-conversion emissions for 480, 520, 550 and $660 \mathrm{~nm}$ whereas for the air annealed sample just the $660 \mathrm{~nm}$ emission was detected. The clear observation of these intra $4 \mathrm{f}$-shell transitions evidences the optical activation of the $\mathrm{RE}$ ions within the $\mathrm{ZnO}$ matrix or at the grain boundaries thanks to a laser annealing treatment.

The laser process is notably affecting the local arrangement of RE ions within the $\mathrm{ZnO}$ lattice, probably Er local surroundings are being changed allowing their optical activation. the appearance of more $\mathrm{ZnO}$ wurtzite structure peaks suggests that the laser treatment is recrystallizing the film, improving the local environment of $\mathrm{Er} 3+$ and $\mathrm{Yb} 3+$ ions, which is translated into more stable levels within the $\mathrm{ZnO}$ band gap This indicates that higher laser power is needed in order to melt the material. This allows the dilution in liquid phase of the RE ions within the $\mathrm{ZnO}$ lattice, allowing their optical activation.

a)

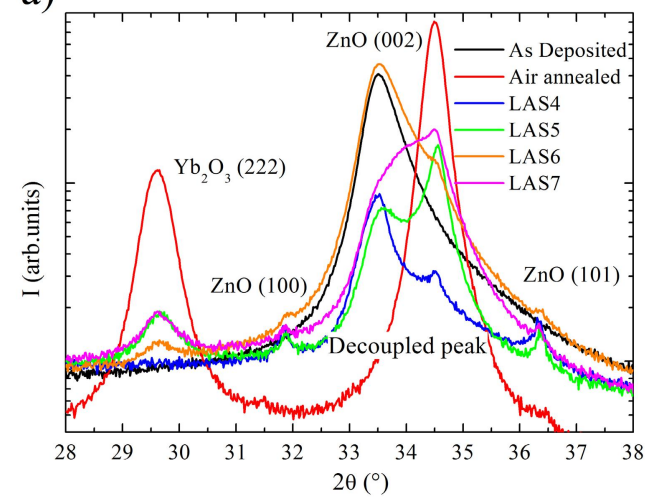

b)

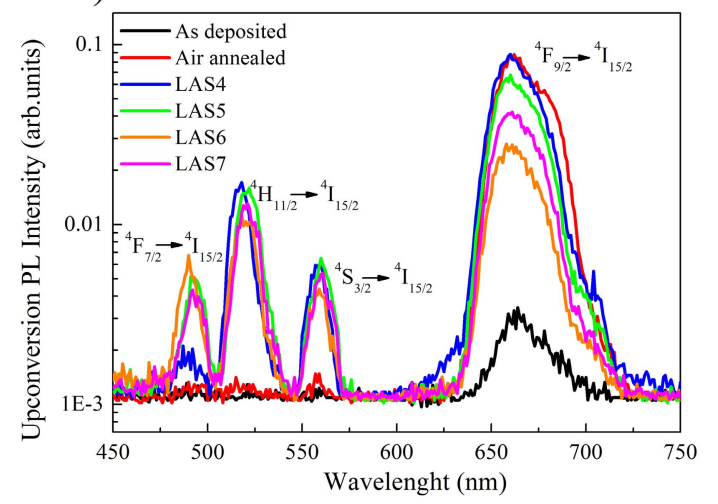

Figure 3. a) X-Ray diffraction patterns and b)up-conversion PL spectra in Logarithmic scale of the ZnO:Er:Yb thin film, as-deposited, annealed in air and laser-annealed at three different laser processes (LAS4, LAS5, LAS6 and LAS7).

Electrical and optical characterization results of the laser-annealed samples along with the as-deposited and the airannealed are presented in Table 5. LAS7 appears as the best irradiation condition with almost no variation of the asdeposited sample $R s$ and with $84.35 \%$ of integrated $T$. 


\begin{tabular}{|c|c|c|}
\hline & $\boldsymbol{R s}(\boldsymbol{\Omega} / \square)$ & $\begin{array}{c}\text { Integrated } \boldsymbol{T}(\mathbf{4 0 0}- \\
\mathbf{1 1 0 0} \mathbf{~ n m}) \mathbf{( \% )}\end{array}$ \\
\hline As-Deposited & $2-10 \mathrm{k}$ & 83.85 \\
\hline Air Annealed & --- & 88.36 \\
\hline LAS4 & $100-130 \mathrm{k}$ & 63.10 \\
\hline LAS5 & $2 \mathrm{M}$ & 78.72 \\
\hline LAS6 & $10 \mathrm{k}$ & 83.74 \\
\hline LAS7 & $\mathbf{2 . 6 k}$ & $\mathbf{8 4 . 3 5}$ \\
\hline
\end{tabular}

Table 5. Optical and electrical characterization results of laser-annealed samples presenting up-conversion emission compared with the as-deposited and air-annealed samples.

\section{CONCLUSIONS}

Preservation of the conductivity of the AZO thin film layer, improvement in the scattering can be achieved through laser texturing with haze values up to almost $40 \%$ at $600 \mathrm{~nm}$ and transmittances higher than $78 \%$. Different patterns have been tested with different roughness and geometries and linear pattern has proven to get the best results amongst the tested structures, especially in the preservation of the conductivity. Laser textured samples have shown higher values of haze and transparency than the reference TCO in a-Si:H technology Asahi-U.

Visible up-conversion emissions at 480, 520, 550 and $660 \mathrm{~nm}$ have been obtained for laser-annealed samples. Laserannealing process was able to optically activate the $\mathrm{RE}$ ions within the $\mathrm{ZnO}$ matrix and showed more up-conversion emission peaks than the conventional thermal annealing in air as it has been demonstrated in this work. Laser-annealed samples present more crystalline orientations of $\mathrm{ZnO}$, as shown in XRD measurements. This evidence the recrystallization of the AZO, suggesting the formation of melted material by the laser processing and subsequent rapid cooling. This melted phase leads to the dilution in liquid phase of the $\mathrm{Er}$ and $\mathrm{Yb}$ atoms in the structure of $\mathrm{ZnO}$ allowing a more effective optical activation than in the conventional annealing in air. Laser-annealed samples preserved the asdeposited film conductivity and are transparent.

\section{REFERENCES}

[1] Nakade S., Compaan A. D., Matulionis I.. Laser scribing of polycrystalline thin films. Optics and Lasers in Engineering, 34(1):15 - 45, 2000.

[2] Vanecek J., Meier E., Vallat-Sauvain N., Wyrsch U., Kroll C., Droz J., Bailat Shah A.V., Schade H.. Thin-film silicon solar cell technology. Progress in Photovoltaics: Research and Applications, 12(2-3):113-142, 2004

[3] Zeman M., Isabella O., Jäger K., Santbergen R., Solntsev S., Topic M., Krc J.. Advanced Light Management Approaches for Thin-Film Silicon Solar Cells. Energy Procedia 15 (2012) 189 - 199

[4] Dominé D, Buehlmann P, Bailat J, Billet A, Feltrin A, Ballif C. Optical management in high-efficiency thinfilm silicon micromorph solar cells with a silicon oxide based intermediate reflector. Phys. Status Solidi RRL 2008; 2:163.198

[5] Sato K, Gotoh Y, Wakayama Y, Hayashi Y, Adachi K, Nishimura H. Highly textured SnO2:F TCO films for aSi solar cells. Rep. Res. Lab. Asahi Glass Co. Ltd. 1992; 42:129-137.

[6] Berginski M, Hüpkes J, Schulte M, Schöpe G, Stiebig H, Rech B, Wuttig M. The effect of front ZnO:Al surface texture and optical transparency on efficient light trapping in silicon thin-film solar cells. J. Appl. Phys. 2007; 101:074903.

[7] Müller J., Schöpe G., Rech B., Schade H., Lechner P., Geyer R., Stiebig H.: Role of the glass/TCO substrate in thin film silicon solar, Proceedings WCPEC-3 Osaka, Japan (2003)

[8] B.M. van der Ende, L. Aarts, and A. Meijerink, Lanthanide ions as spectral converters for solar cells, Phys. Chem. Chem. Phys. 11 (2009) 11081-11095.

[9] J.F. Philipps, T. Töpfer, D. Ehrt, and R. Sauerbrey, Spectroscopic and lasing properties of Er3+:Yb3+-doped 
fluoride phosphate glasses, Appl. Phys. B. 405 (2001) 399-405.

[10] A.S. Oliveira, M.T. de Araujo, A.S. Gouveia-Neto, J.A. Medeiros Neto, A.S.B. Sombra, and Y. Messaddeq, Frequency upconversion in Er3+/Yb3+-codoped chalcogenide glass. Appl. Phys. Lett. 72 (1998) 753.

[11] M. Wang, C. Mi, W. Wang, C. Liu, Y. Wu, Z. Xu, B. Mao, and S. Xu, ACS nano. 3 (2009) 1580-1586.

[12] M. Lluscà, J. López-Vidrier, A. Antony, S. Hernández, B. Garrido, J. Bertomeu, Up-conversion effect of Erand Yb-doped ZnO thin films, Thin Solid Films, 562 (2014) 456-461.

[13] M. Ishii, S. Komuro, T. Morikawa, and Y. Aoyagi,. Local structure analysis of an optically active center in Erdoped $\mathrm{ZnO}$ thin film J. Appl. Phys. 89 (2001) 61-68.

[14] JCPDS card No 41-11506.

[15] L. Douglas, R. Mundle, R. Konda, C. E. Bonner, A. K. Pradhan, D. R. Sahu, and J.L. Huang Influence of doping rate in Er3+:ZnO films on emission characteristics, Opt. Lett. 33 (2008) 815-7.

[16]Z. Zhou, T. Komaki, A. Koizumi, T. Komori, M. Yoshino, M. Morinaga, Y. Fujiwara and Y. Takeda, Photoluminescence around $1.54 \mu \mathrm{m}$ from Er-containing $\mathrm{ZnO}$ at Room Temperature Mater. Trans. 45 (2004)

2003-2007

\section{ACKNOWLEDGMENTS}

This work has been supported by the Spanish Ministerio de Economía y Competitividad and the European Regional Development Fund through the projects AMIC (ENE2010-21384-C04-03), HELLO (ENE2013-48629-C4-2-R), LEOMIS (TEC2012-38540-C02$01)$ and INNDISOL (IPT-420000-2010-6) 